\title{
Lorenzo Hervás y Panduro SJ (1735-1809) y su posición ilustrada sobre la astrología.
}

Lorenzo Hervás y Panduro SJ (1735-1809) and his enlightened opinión about astrology

Nicolás Hernán Perrone*

\section{Resumen}

En el siguiente trabajo nos propondremos analizar las opiniones del jesuita español expulso Lorenzo Hervás y Panduro sobre la astrología y otras disciplinas esotéricas. Para esto estudiaremos puntualmente dos de sus obras: Historia de la Vida del Hombre. Tomo I y Viage Estático al Mundo Planetario. En ambos libros Hervás busca la difusión del conocimiento científico -médico y astronómico, respectivamente- para un público sin conocimientos del mismo. Comparando este esfuerzo de divulgación con la obra del temprano siglo XVIII de Jeronimo Benito Feijoo buscaremos observar los diferentes acercamientos que ambos clérigos ilustrados tienen respecto de las prácticas esotéricas y supersticiosas.

Palabras clave: astrología, esoterismo, superstición, Compañía de Jesús, Lorenzo Hervás y Panduro

\begin{abstract}
In the following article we will analize the opinion of the expelled Spanish Jesuit Lorenzo Hervás y Panduro about astrology and other esoteric disciplines. For this purpose we will study two of his works: Historia de la Vida del Hombre. Tomo I y Viage

* CONICET - IDAES / IESH - UNLPam (Instituto de Estudios Socio-Históricos de la Facultad de Ciencias Humanas de la Universidad Nacional de La Pampa).
\end{abstract}


Estático al Mundo Planetario. Both books try to offer to its not-scientifically-educated audience an abridgment of the scientific knowledge -medical science and astrology, respectively- of that time. We will try to compare this effort with the writings from the early XVIII century of Jeronimo Benito Feijoo, in order to observe the different approaches of both clerics to the esoteric and superstitious practices.

Key Words: astrology, esotericism, superstition, Society of Jesus, Lorenzo Hervás y Panduro

Recibido: 8 de mayo de 2015

Evaluado: 18 de mayo de 2015 


\section{Introducción}

Desde su nacimiento en el siglo XVI, en pleno desarrollo de la Contrarreforma, la Compañía de Jesús ha sido asociada, no sin buenas razones, por la historiografía especializada a la estrecha defensa de la ortodoxia católica, del Papado y de sus posiciones teológicas. Por este motivo, podría sostenerse que los vínculos entre los seguidores de San Ignacio la astrología no fueron del todo amigables durante la Edad Moderna. Aunque nunca habían sido aceptadas del todo por la alta cultura teologal católica, las prohibiciones explicitas por parte del papado a las practicas divinatorias y astrológicas, por ejemplo mediante la famosa bula Coeli et terrae de Sixto V, generaron en todo el mundo católico, y en particular dentro de la Compañía de Jesús, un rechazo a tales actividades, al menos en el plano formal e intelectual.

Sin embargo, la relación de los seguidores de San Ignacio con las disciplinas esotéricas, ${ }^{1}$ entre ellas las astrología, no fue tan lineal como podría suponerse. Desde sus comienzos, la Compañía de Jesús tuvo entre sus filas a varios miembros que no solo coquetearon, a pesar de las vedas papales, con aquellas disciplinas sino que se aplicaron seriamente a su estudio y práctica. Quizás uno de los personajes más relevantes relacionados con el esoterismo en los primeros años de la Compañía de Jesús fue el cabalista y astrónomo Guillaume Postel. En 1544 ingresó en la Compañía cuando ya era un intelectual reconocido en la Europa del momento. No obstante, el propio San Ignacio de Loyola lo expulso al año siguiente por sostener opiniones incompatibles con los principios de la Compañía. Algunos años más tarde, San Ignacio reveló que la expulsión de Postel se debió particularmente a causa de sus predicciones y profecías. En 1562, Postel pidió la reincorporación a la Compañía de Jesús a Laínez, el sucesor de San Ignacio, aunque fue rechazado nuevamente ${ }^{2}$.

Sin embargo, el jesuita más reconocido con estrechos contactos con el mundo de la magia ha sido, sin dudas, Atanasio Kircher. Sobre este curioso personaje la historiografía especializada en la Compañía de Jesús, en la historia de la Ciencia o en la cultura barroca ha publicado en los últimos años innumerables libros y artículos. Muchos aspectos de su vida intelectual han sido profundamente estudiados: desde su rol como curador del barroco museo del Colegio Romano hasta sus tratados sobre geología, magnetismo, óptica o sinología. ${ }^{3}$ En particular, la obra de Kircher que está más relacionada con las prácticas mágicas es su famoso Oedipus Aegyptiacus. El objetivo de nuestro jesuita en esa obra era traducir los jeroglíficos egipcios -objetivo, obviamente, no cumplido a pesar de lo que el mismo Kircher pensara-, los cuales, sostenía Kircher, contenían una mezcla de sabiduría esotérica con magia supersticiosa. Aunque libros con contenidos similares a los del Oedipus fueron rápidamente incluidos en el Index, la obra de Kircher fue publicada y difundida sin inconvenientes gracias al beneplácito del emperador Fernando III y del papa Inocencio X. Su preeminencia como autor reconocido por la intelectualidad europea logró cierta inmunidad para sus escritos e investigaciones. Sin embargo, eso no evito que grandes partes de su obra fueran duramente criticadas por los mecanismos de censura interna de la Compañía de Jesús.

\footnotetext{
${ }^{1}$ Tomamos la definición de esotérico a partir de la descripción que se encuentra en la Introducción de Bubello, 2010: 18

${ }^{2}$ O' Malley, 1994: 57

${ }^{3}$ Acuña, 2004; Findlen, 2003; Millones Figueroa, 2005.
} 
La principal crítica de los censores jesuíticos a la obra de Kircher -que finalmente no fue tenida en cuenta gracias al apoyo interno del Prepósito General Gottifreddi- fue la mención en el Oedipus de numerosas prácticas mágicas y cabalísticas y "supersticiones peligrosas" 4 .

No fue Kircher el último jesuita en estudiar y difundir conocimientos esotéricos. Como demuestra un interesante estudio de caso sobre el colegio jesuítico de Santo Antão en Lisboa, varios profesores de la Compañía dictaron cursos sobre astrología y quiromancia hasta los primeros años el siglo XVIII. Los conocimientos prácticos que podían extraerse del estudio de la astrología eran útiles, en una ciudad marítima como Lisboa, para el arte de la navegación. Debido a que el origen social de mucho de los estudiantes de este colegio jesuítico era relativamente humilde, la astrología proveía de una serie de saberes que podían aplicarse en la práctica náutica sin necesariamente necesitar conocimientos científicos previos. En estos cursos, los profesores de la Compañía distinguían a las practicas astrológicas licitas e ilícitas, siendo la astrología natural aquella que era permitida y la astrología judiciaria aquella que era totalmente prohibida $^{5}$.

Todos estos ejemplos a lo largo de la historia de los hijos de San Ignacio, nos demuestran que la imagen de una monolíticamente ortodoxa Compañía de Jesús necesita ser matizada al menos en lo que refiere a su relación con las disciplinas esotéricas. ${ }^{6}$ Sin embargo, es necesario reconocer que la Compañía ha aportado numerosos teólogos que han dado decisivos aportes a las polémicas anti-mágicas en la Europa Moderna. Entre los más relevantes podemos citar, sin duda, tanto a Francisco Suarez con su obra De religione y a Martin del Rio con su tratado Disquisitionum magicarum $^{7}$. El gran peso e influencia intelectual, tanto dentro como fuera de la Compañía de Jesús, de estos jesuitas hace que no podamos desconocer -a pesar de todas los necesarios matices- la importancia del pensamiento anti-esotérico dentro de la Compañía de Jesús.

Ahora bien, el objetivo de este breve estudio es analizar la postura puntual de Lorenzo Hervás y Panduro S.J. (1735-1809) sobre la astrología. Intentaremos ver, luego de analizar brevemente su biografía, sus obras y el contexto histórico donde desarrollo su actividad intelectual, que opina este jesuita de finales del siglo XVIII sobre las ciencias divinatorias y el porqué de sus opiniones.

\footnotetext{
${ }^{4}$ Stolzenberg, 2007.

${ }^{5}$ Leitao, 2007.

${ }^{6}$ Todos los conflictos teológico-políticos que tuvieron los jesuitas desde sus orígenes nos hacen pensar seriamente sobre la efectiva homogeneidad "ortodoxa" institucional de la Compañía de Jesús. Las acusaciones de "alumbradismo" en los primeros anos, el conflicto con el papado en relación a las misiones de India y China, la asociación de la Compañía de Jesús con el regicidio o el probabilismo, son algunas de las polémicas en las que estuvo involucrada la Compañía en los doscientos años desde su creación hasta su supresión.

${ }^{7}$ Entre otros tratados contra la astrología escritos por jesuitas podemos citar también el Adversus fallaces et superstitiosas artes (1591) de Benito Pereira y el In astrologos coniectores libri quinque (1615) de Alessandro de Angelis. Citados en: Leitao, 2007.
} 


\section{Lorenzo Hervás y Panduro, jesuita expulso ilustrado, y su obra}

Nuestro autor nació en 1735 en Horcajo de Santiago, una pequeña villa manchega. Hijo menor de una pareja de labradores, entró a la Compañía de Jesús en 1749 ya que estaba interesado en seguir una carrera literaria y sus escasos recursos familiares no se lo permitían. Se educó en el noviciado de Madrid en donde sobresalió en matemáticas y astronomía. Fue ordenado sacerdote y dedicó los años anteriores a la expulsión de los jesuitas de España a dar clases en el colegio jesuítico de Cáceres y en el seminario de Nobles de Madrid. Expulsado en 1767, se estableció en Italia en Forli y en Cesena. Desde el exilio itálico publicó sus más importantes obras y se estableció como un pensador reconocido dentro y fuera de la Compañía, siendo un miembro activo de la República de las Letras. Los últimos años de su vida, con un breve intervalo de cuatro años en los cuales regresó frustradamente a su país natal, los paso en Roma, donde Pío VII le otorgó el cargo de bibliotecario del palacio Quirinal. Murió en Roma en 1809 luego de una prolífica vida de investigaciones en los más diversos temas. El exilio en Italia le permitió a Hervás poder dedicarse a su carrera literaria y académica con más libertad. Allí desarrolló una extensa bibliografía que incluyó tratados de lingüística, antropológicos, cosmológicos y teológicos. Además de mantenerse gracias a mecenazgo de algunos nobles italianos y al sueldo de clérigo recibido del Estado español, vivió muchos años de su profesión de autor y de los derechos de sus obras ${ }^{8}$.

En este trabajo estudiaremos puntualmente dos de sus obras para rastrear las opiniones de Hervás sobre la astrología: Historia de la Vida del Hombre. Tomo I. Concepción, Nacimiento, Infancia y Niñez del Hombre (1789) y Viage Estático al Mundo Planetario en el que se observan el mecanismo y los principales fenómenos del Cielo; se indagan sus causas físicas; y se demuestra la existencia de Dios, y sus admirables atributos (1793-4). Ambas obras forman parte de un proyecto de divulgación científico-enciclopédico que Hervás escribió originalmente en italiano titulado Idea dell' Universo, y que comenzó a publicar en 1778. Posteriormente, nuestro autor amplio, tradujo, editó y publicó en España su obra. Estas ediciones ampliadas en castellano son las que estudiaremos a continuación ${ }^{9}$.

Historia de la Vida del Hombre es una obra donde Hervás describe, a lo largo de siete extensos tomos, las etapas del desarrollo biológico/espiritual del hombre, desde la formación del feto, su nacimiento y posterior bautismo hasta su muerte, funeral y futura resurrección del cuerpo y del espíritu. A lo largo de estos tomos Hervás ofrece a sus lectores no solo descripciones anatómico/médicas sobre el funcionamiento del cuerpo humano en las distintas etapas de la vida de una persona, sino que también da numerosos consejos sobre las enfermedades que afligen al hombre, sobre el mejor tipo de educación que ofrecer a un joven o sobre los problemas de la vejez, por dar algunos ejemplos sobre la variedad de tópicos cubiertos por Hervás en esta obra. Más allá del contenido en sí mismo, nuestro jesuita intenta siempre ofrecer a sus lectores un compendio del conocimiento médico/científico de su época en una manera en que les sea accesible y útil.

\footnotetext{
${ }^{8}$ Existen varias biografías y trabajos sobre la prolífica obra de Hervás y Panduro: Caballero, 1868; Gardia Paredes Aued, 1964; Justo, 2001. Sin embargo al día de la fecha la biografía más completa es sin dudas la de Astorgano Abajo, 2010. Existe una página web exclusivamente dedicada a la figura de Hervás y Panduro y a su producción escrita: http://www.cervantesvirtual.com/portales/lorenzo_hervas_y_panduro/

${ }^{9}$ Hervás y Panduro, (1793-4); Hervás y Panduro, (1789).
} 
La otra obra que analizaremos, el Viage Estático, sigue la misma línea de difusión científica que se observa en Historia de la Vida del Hombre, aunque en este caso Hervás se dedique al conocimiento astronómico. A pesar de que Hervás y Panduro no haya estado completamente actualizado con los últimos avances científicos de su época, ${ }^{10}$ intenta dar a sus lectores un tratado de astronomía accesible para gente ajena a la disciplina sin complicadas explicaciones matemáticas o físicas. La obra está escrita, como puede deducirse de su propio título, como si fuera un viaje imaginario alrededor del Sistema Solar, comenzando por el Sol y terminando en Urano -descubierto recientemente en $1781^{11}$. A lo largo de este viaje mental Hervás guía a sus lectores por cada planeta explicando sus características, mostrando la distancia que los separa de la Tierra y describiendo como se verían los cielos desde la perspectiva de cada planeta. Sin embargo, nuestro jesuita va más allá de las descripciones astronómicas. En varias parte de su obra realiza extensos excursus relacionados solo tangencialmente con los temas tratados: por ejemplo en el capítulo dedicado al Sol Hervás comenta a sus lectores como desde el inicio de los tiempos la mayoría de las civilizaciones cayeron en la idolatría al adorar como divinidad al Astro Rey. Volveremos sobre este punto más adelante.

Por último, además de sus tratados de difusión científica Hervás y Panduro escribió casi simultáneamente dos obras en 1793 que debemos mencionar ya que, aunque no estén directamente relacionadas con el objeto de este trabajo, serán tenidas en cuenta más adelante en este trabajo. Nos estamos refiriendo a Causas de la Revolución de Francia en el año 1789, y medios de que se han valido para efectuarla los enemigos de la religión y del estado y a la Biblioteca Jesuítico-española (1759-1799). ${ }^{12}$ El primer libro es un tratado político cuyo objetivo es buscar las causas "morales" de la Revolución Francesa en una antigua conspiración político-teológica contra el Trono y el Altar urdida por las cuatro "sectas" enemigas de la Iglesia: los calvinistas, los jansenistas, los filósofos ilustrados y la masonería. Esta obra le valió luego la reputación a Hervás de ser uno de los padres del pensamiento reaccionario español ${ }^{13}$. La Biblioteca Jesuítico-española es un catalogo bio-bibliográfico de casi 500 jesuitas iberoamericanos de la época de las expulsiones y supresión de la Compañía de Jesús. En esta obra Hervás intento reivindicar a la suprimida Compañía mostrando la ingente producción intelectual y literaria de los jesuitas. De este catalogo se puede obtener información no solo sobre los jesuitas más conocidos del periodo, sino también sobre pequeñas figuras poco conocidas por la historiografía especializada. De la misma manera, gracias a los contactos de Hervás y su labor recopiladora se puede tener un detalle bastante preciso sobre la producción bibliográfica de la colectividad de jesuitas expulsos y, por lo tanto, tener una idea de cuáles eran sus preocupaciones literarias ${ }^{14}$.

Antes de comenzar a analizar la postura de Hervás y Panduro sobre la astrología de debemos decir algunas palabras sobre el contexto intelectual en el que se desarrollo intelectualmente Lorenzo Hervás y Panduro: la Ilustración española y la tradición supersticiosa cristiana.

\footnotetext{
${ }^{10}$ Justo, 2001: LVIII

${ }^{11}$ Por obvias razones, Neptuno y Plutón, descubiertos recién en el siglo XIX y XX, no son mencionados en el Viage Estático.

${ }^{12}$ Hervás y Panduro, 1807; Hervás y Panduro, 2007.

${ }^{13}$ Herrero, 1988: 151-180

${ }^{14}$ Perrone, 2012; Perrone, 2010.
}

8 Nicolás Perrone. Lorenzo Hervás y Panduro SJ (1735-1809) y su posición ilustrada... 56-87. 


\section{La Ilustración española y la lucha contra las supersticiones}

La Ilustración española -cuya raíz se remonta a los novadores del s. XVII- ${ }^{15}$ posee algunas características que la distinguen de sus hermanas europeas. La diferencia más evidente fue, sin duda, el catolicismo dominante en la mayoría de los pensadores españoles. A diferencia del ateísmo o deísmo de sus pares franceses e ingleses, la ortodoxia católica no fue cuestionada, salvo contados casos, por la mayoría de los ilustrados españoles; es por eso que tampoco pudieron dar rienda suelta a las audacias intelectuales de sus vecinos del norte ${ }^{16}$. Sin embargo, ni el apego a la fe de Roma, ni las trabas inquisitoriales detuvieron el ingreso de las nuevas teorías filosóficas y científicas. La nueva filosofía fue conocida en España desde el comienzo, aunque sólo aceptada y cultivada por unos pocos.

Estas nuevas ideas, introducidas por unas minorías combativas, entraron rápidamente en conflicto con el status quo científico y académico español. Si bien pensadores como Bacon, Galileo, Descartes y Newton -entre otros- no fueron desconocidos en España, su aceptación no fue inmediata y su difusión no estuvo exenta de dificultades ${ }^{17}$. En el caso de Hervás es interesante ver como en el Viage estático batalló en dos frentes simultáneos: por un lado, contra el ateísmo y el materialismo, nacidos como consecuencia de las nuevas filosofías y combatidos por la apologética católica del momento. Por el otro lado, emprendió una ardua lucha contra la física peripatética que se mantenía casi incólume en las universidades españolas aun a fines del siglo XVIII ${ }^{18}$.

Podríamos decir, entonces, que las Luces españolas si bien no desconocieron los avances de la Europa del momento, tampoco avanzaron a su ritmo. En palabras del hispanista Sarrailh: "el soplo del siglo XVIII fue más violento y poderoso en las cimas"19. Inquieta por su "atraso" comparativo España intentó seguir el camino de un reformismo ilustrado preocupado más por las mejoras en la educación, la agricultura, la industria y las aplicaciones prácticas de los avances científicos que por las implicancias de las nuevas ideas filosóficas ${ }^{20}$. Los pensadores españoles interesados por mejorar con la cultura y el conocimiento el atraso de su península, siguieron varias ideas eclécticamente basadas en el pensamiento científico experimentalista ${ }^{21}$. Este reformismo ilustrado español poseía como una de sus ideas guías a la Utilidad, concepto que Hervás hilará frecuentemente entre los párrafos de su Viage estático. La búsqueda de la Utilidad común, unida siempre a la Felicidad pública -concepto debidamente secularizado-, justificaba siempre los deseos de renovación y actualización

\footnotetext{
${ }^{15}$ García Cárcel, 1998.

${ }^{16}$ Fernández Sebastián, 1998.

${ }^{17}$ Ya el copernicanismo, por ejemplo, era conocido en el s. XVI y XVII. Los novadores continuaran durante el s XVII con los intentos de difundir las nuevas ideas físicas y matemáticas. Sus seguidores del s. XVIII contaran con más éxito durante el reinado de Carlos III (García Cárcel, 1998).

${ }^{18}$ Sarrailh, 1981: 137

${ }^{19}$ Ibid: 708.

${ }^{20}$ El topos del "atraso español" fue a lo largo de todo el siglo XVIII y parte del XVII el leit motiv de la intelectualidad española (Albiña, 1994).

${ }^{21}$ Sánchez-Blanco Parody, 1991.
}

9 Nicolás Perrone. Lorenzo Hervás y Panduro SJ (1735-1809) y su posición ilustrada... 56-87. 
de las ciencias y las industrias de España ${ }^{22}$.

En el plano religioso la Ilustración en España no significo una crítica a la religión católica en sí misma, sino más bien un intento de reformar lo que los pensadores ilustrados consideraban los "abusos" de la Iglesia. Las críticas de los reformadores eran múltiples: el excesivo número del clero regular, la ignorancia generalizada de los sacerdotes, el improductivo uso de la tierra por parte de la Iglesia, la ostentación y el lujo de los prelados, la cerrazón ante las nuevas ideas científicas y los abusos cometidos en la veneración de reliquias, santos u en otras creencias populares consideradas "supersticiosas" 23 .

Es particularmente en esta última línea crítica que podemos enmarcar a una de las figuras más reconocidas de la ilustración española: el fraile benedictino Benito Jerónimo Feijoo. En Teatro crítico universal, su obra más famosa, Feijoo buscó desenmascarar, con espíritu ilustrado y no poco sarcasmo, numerosas creencias o practicas populares. Entre ellas podemos incluir la existencia de vampiros, algunas peregrinaciones y milagros populares y, lo que es más relevante para este articulo, la creencia en la efectividad de la alquimia, la astrología y demás artes divinatorias ${ }^{24}$.

Sin embargo, esta lucha ilustrada de Feijoo no es sino parte de la historia mucho más extensa de las continuas redefiniciones, por parte de los teólogos católicos, del concepto de "superstición" que llevaron a numerosas y continuas campañas de persecución, organizadas por las jerarquías eclesiásticas, contra las creencias y practicas populares consideradas heterodoxas. Aunque en los comienzos del pensamiento cristiano eran consideradas supersticiosas todas las prácticas religiosas y cultuales no cristianas -prácticas religiosas siempre orientadas a la adoración del demonio, según los teólogos católicos-, con el avance del cristianismo y el retroceso de las religiones de la antigüedad fue necesario precisar donde seguía residiendo "lo supersticioso". Fueron las "prácticas vanas" -el uso de amuletos, los rituales religiosos populares no autorizados y la creencia en la magia, la astrología u otras artes divinatorias, por citar solo algunos ejemplos- las que terminaron siendo condenadas por la alta cultura teologal como "supersticiosas".

Según este "modelo cristiano de superstición”, estas prácticas eran supersticiosas porque la gente esperaba de las cosas efectos que no pueden producirse por sus atributos naturales. La imposibilidad que, por ejemplo, un amuleto surta efecto por sus elementos constituyentes o por las formulas mágicas aplicadas al mismo, o que pueda adivinarse el futuro por medio de las estrellas se debe a que ni las formulas que se suponen mágicas ni las estrellas tienen la capacidad para realizar aquello que se les pide hacer. No obstante, para poder determinar lo que es posible o no dentro de la Naturaleza, el pensamiento teológico cristiano debió establecer un complejo sistema de causalidades. De acuerdo con este modelo existieron tres órdenes de causalidad: el sobrenatural, el natural y el preternatural. El primer orden correspondía a Dios y todo lo que podía hacer, el segundo orden de causalidad estaba relacionado con lo que era posible dentro del reino de lo creado por Dios, es decir con las propiedades naturales de las creaturas.

\footnotetext{
${ }^{22}$ Hazard, 1988.

${ }^{23}$ Sarrailh, 1981: 612-660.

${ }^{24}$ Campagne, 2002: 96-97.
}

10 Nicolás Perrone. Lorenzo Hervás y Panduro SJ (1735-1809) y su posición ilustrada... 56-87. 
Por último, el orden preternatural determinaba la manera en que los ángeles y los demonios podían intervenir la Naturaleza. Todo lo que no podía ser explicado por la causalidad natural o por la intervención divina tenía que, según este esquema explicativo, serlo por la intervención de fuerzas preternaturales, es decir, generalmente por fuerzas demoniacas. Recapitulando, las prácticas no cultuales condenadas por la Iglesia, como por ejemplo la astrología, eran supersticiosas porque para que fueran efectivas presuponían la intervención de los espíritus malignos ${ }^{25}$.

Ahora bien, si volvemos a Feijoo y su crítica ilustrada a las supersticiones veremos que el fraile benedictino asume plenamente este modelo tripartito. La principal crítica que realiza a la astrología no es que realiza predicciones erróneas, sino todo lo contrario: sus predicciones son tan amplias, generales y ambiguas que es imposible que los astrólogos puedan equivocarse ${ }^{26}$. De la misma manera, cuestiona, por ejemplo, la imposibilidad que tienen los astrólogos de percibir con exactitud la posición de los astros, los distintos métodos que han tenido a lo largo de los años, y los problemas que tienen para establecer la causalidad de los hechos. Al rechazar a la astrología lo hace suponiendo la total imposibilidad natural de las predicciones generadas por ella. Sin embargo, Feijoo no niega la posibilidad de que puedan intervenir en las predicciones astrológicas espíritus malignos:

"Últimamente, pueden también tener alguna parte en estas predicciones el demonio, el cual, si los futuros dependen precisamente de causas necesarias o naturales, puede con la comprehension de ellas antever los efectos. Pongo por ejemplo la ruina de una casa, porque penetra mejor que todos los arquitectos del mundo el defecto de su contextura (...), y aqui con bastante probabilidad puede, por consiguiente, avanzar la muerte del dueño, si es por genio retirado a su habitación. Aun en las mismas cosas que dependen del libre albedrío puede lograr el demonio bastante acierto con la penetración grande que tiene de inclinaciones, genios y fuerzas de los sujetos, y de lo que el mismo ha de concurrí al punto destinado con sus sugestiones. Por esto son muchos, y entre ellos San Agustín, de sentir, que algunos, que en el mundo suenan profesar la judiciaria, no son dirigidos en sus predicciones por las estrellas, sino por el oculto instinto de los espíritus malos”,27.

Es decir, a pesar de su espíritu crítico ilustrado Feijoo no puede negar la existencia y la posibilidad de intervención demoniaca ya que estaría socavando una parte importante del edificio teológico cristiano. De esta manera, con Feijoo, como con otros ilustrados católicos, se pueden observar los límites de la Ilustración española: la lucha reformista contra las "supersticiones" dentro del marco conceptual del cristianismo se frenó donde otros pensadores contemporáneos siguieron avanzando.

Mientras que en sus orígenes el pensamiento cristiano considero superstición a toda creencia religiosa ajena a las verdades cristianas y luego a toda practica que no

\footnotetext{
${ }^{25}$ Ibid.: 81-98.

26 “¿Que nos pronostican estos Judiciarios, sino unos sucesos tan comunes, sin determinar lugares, ni personas; los quales considerados en esta vaga indiferencia, seria milagro que faltasen al mundo?” (Feijoo, 1778: 190).

27 Cita extraída de: Campagne, 2002: 97-98.
}

11 Nicolás Perrone. Lorenzo Hervás y Panduro SJ (1735-1809) y su posición ilustrada... 56-87. 
pudiera reducir al sistema de tripartito de causalidad ya explicado, con la llegada de la Ilustración el "modelo cristiano de superstición” fue paulatinamente reemplazado por el "modelo científico-racionalista de superstición”. Según este nuevo esquema -que surgió durante el siglo XVIII, tuvo su mayor ímpetu en siglo XIX con el positivismo, y es el que podríamos decir que continúa imperante en nuestra sociedad- las mismas creencias religiosas comienzan a ser tildadas de superstición. El avance de la ciencia a lo largo de esos dos siglos fue dando más información sobre el funcionamiento de la Naturaleza y, por lo tanto, un entendimiento más completo sobre las causalidades del mundo natural: ya no eran necesario recurrir a los ordenes sobre y preternatural para explicar los fenómenos de la naturaleza. Por lo tanto, según este esquema todo lo que no puede ser demostrado mediante el método científico es menospreciado de la misma forma en que los teólogos cristianos desprestigiaban a otras religiones o a numerosas prácticas populares $^{28}$.

Ahora bien, ¿en cuál de los dos modelos podremos ubicar a Hervás y Panduro y a su crítica a la astrología?

\section{Lorenzo Hervás y Panduro y su crítica a la astrología}

Lo primero que debemos aclarar sobre la posición de Hervás y Panduro sobre la astrología es que nuestro jesuita escribió verdaderamente muy poco al respecto a lo largo de toda su obra. Si bien las obras de Feijoo y de Hervás tienen muchos puntos en común - ambos se dedicaron a la divulgación del pensamiento científico, por ejemploes notable la diferencia respecto al espacio dedicado a la refutación de esta arte divinatoria. Mientras que el monje benedictino dedica más de diez capítulos, distribuidos a lo largo de 8 tomos de su Teatro Critico, a atacar a las disciplinas esotéricas (la magia, la alquimia y la astrología, a la cual le dedica puntualmente todo un capitulo) y algunas creencias populares, Hervás y Panduro dedica solo algunas breves páginas a este tema en su igualmente extensa obra. Las obras en las cuales ataca a la astrología son las obras ya mencionadas: Historia de la Vida del Hombre y el Viage Estático.

No solo Hervás dedica pocas páginas a hablar sobre la astrología, sino que tampoco se toma mucho trabajo para refutar las prácticas o creencias de esta disciplina. Directamente nuestro jesuita considera que la astrología "lexos de ser ciencia, es verdadera y supersticiosa ignorancia” ${ }^{29}$ y, aunque sigue en lo básico las ideas de Feijoo, despacha en estas rápidas líneas sus consideraciones sobre ella:

"El concurso de fenómenos celestiales es tan inútil para influir sobre el ánimo del infante, o sobre su fortuna o desgracia, como para el mismo fin son inútiles la diferencia o semejanza de sitios tiempos o conveniencias temporales. La bondad o malicia de las obras son consequencias necesarias de la libertad humana; la hermosura o fealdad del cuerpo son efectos de la naturaleza; y la que se dice buena o mala suerte en las cosas temporales, depende en parte del

\footnotetext{
28 Ibid: 100-112.

${ }^{29}$ Hervás y Panduro, 1789: 140.
} 
conocimiento y prudencia del Hombre; y en parte de la combinación de ciertas causas, cuyo conocimiento está reservado solo al Supremo Hacedor. A estos principios, según la razón y Religión se reduce toda la doctrina del arte divinatoria” ${ }^{30}$.

En el Viage Estático Hervás y Panduro desarrolla un poco más sobre la posibilidad que tienen los astros de influir en la tierra y en los destinos de los hombres:

"Esta larga doctrina, que he querido darte, Cosmopolita, sobre el fingido influxo de los astros, y principalmente del lunar, porque la juzgo utilísima al hombre, y dignísima de su mayor atención, concluiré reduciéndola a pocas palabras, claras y decisivas. En los astros se pueden concebir diversos influxos, que llamaremos morales, animales, vegetales, meteorológicos y mecánicos sobre los cuerpos terrestres. Los influxos morales son los que se refieren a las costumbres y al destino de los hombres, y tales influxos no existen en los astros. Los influxos animales son los que se pueden concebir propios para alterar la sanidad de los hombres y de los animales, y para alargarles o acortarles la vida; tampoco en los astros existen tales influxos (...).

Los influxos vegetales y meteorológicos consisten en calentar, fomentar, promover, alterar y desordenar los cuerpos terrestres; y estos influxos son relativos a las estaciones del año, y a la calidad de la atmósfera regional. Los influxos mecánicos estrivan en la presión, atracción o repulsión, que unos cuerpos causan mediata o inmediatamente en otros por razón de su movimiento, peso y virtud atractiva o repulsiva. Al influxo mecánico de la atracción de la Luna y el Sol, atribuyen los Físicos modernos el movimiento continuo de fluxo y refluxo, que se advierte en los mares terrestres. De este influxo mecánico trato en mi historia física de la Tierra, a la que propiamente pertenece: basta haberte dado esta noticia, si la juzgas no indigna de tu curiosidad para leer mi discurso sobre las mareas terrestres, de las que no debo hablar más para no mezclar la historia celeste con la terrestre, que ahora es objeto de nuestro viage, estudio y atención. A este breve discurso se reduce mi opinión sobre el influxo de los astros" $^{31}$.

Es decir, Hervás sostiene que los únicos influjos que actúan sobre la superficie terrestre son aquellos que son explicados según la meteorología y la física atraccionaria de Newton. Aquellos influjos que, se supone, modifican el libre albedrío del hombre nuestro jesuita los considera directamente falsos sin extenderse más sobre ese asunto.

Pero las ideas newtonianas no solo sirven para mostrar cuales son las únicas influencias posibles de los cuerpos planetarios en la Tierra, también sirven para despejar los temores que desde la antigüedad tuvieron todos los pueblos de la tierra hacia los cometas y sus nefastas influencias. En el tomo IV del Viage Estático Hervás y Panduro, luego de ofrecer un extenso discurso sobre los cometas, sus características, sus orbitas y la periodicidad de su aparición por la Tierra, dedica un breve apartado sobre las creencias de los antiguos acerca de los cometas. Los mismos, nos relata Hervás,

\footnotetext{
${ }^{30}$ Ibid: 142.

${ }^{31}$ Ibid, (1793-4) Tomo III: 169-170.
} 
provocaban en ellos un "terror que hasta hoy se conserva en el vulgo, y por algunos sabios modernos se pretende autorizar con la algebrayca confusión del respetable calculo, fundado en hipótesis arbitrarias" ${ }^{32}$. Sin embargo:

"Llego el tiempo, en que al oírse las escuelas filosóficas de los terrícolas el ruidoso sistema atraccionario que se publico en 1686 por Newton, ellos repentinamente transformados y envestidos de nuevas ideas, empezaron luego a mirar los fenómenos celestes, y principalmente la aparición de los cometas, con la misma diferencia con que ven la alternativa sucesión de las estaciones anuales, y tal vez, con el placer con que miran la lucha de los elementos terrestres. Entonces, Cosmopolita mío, desaparecieron repentinamente los temores vanos, y los melancólicos augurios que se hacían al aparecer los cometas" 33 .

En palabras de Hervás: "Si los sabios de la antigüedad hubieran tenido las luces que dirigen a los de nuestro tiempo, no hubieran caído en tan groseros despropósitos”. Son las luces de la ciencia newtoniana las que despejan las creencias y temores ignorantes dignos solamente del vulgo.

No obstante, Hervás es un poco ambiguo de lo que él supone respecto de las creencias del bajo pueblo cristiano. Aunque, como vimos más arriba, en el Viage Estático nuestro autor nos señala que solo el vulgo conserva el temor a los cometas luego del avance de la ciencia, en un apartado de Historia de la Vida del Hombre Hervás afirma lo siguiente:

"La Religión Christiana, mas que todas las ciencias, ha iluminado hasta los más rudos que la profesan, para que sobre el arte divinatoria piensen con mayor acierto que los Letrados antiguos, y los más Sabios de otras sectas. Al vulgo mismo del Christianismo es notorio y patente por razón y máxima de Religión, que el nacer un Hombre en tal hora, o en la conjunción u oposición de algunos planetas, o en la aparición de cometas, es cosa tan indiferente como nacer en la ciudad, o en la aldea; en la población, o en el campo; en el palacio, o en la choza; en el tiempo lluvioso o seco; por la mañana o por la tarde”34.

Mientras que la ciencia newtoniana fue aquella que despejó las sobras de la ignorancia en los sabios, el cristianismo hizo exactamente lo mismo pero para el pueblo rudo. De esta manera, según Hervás, el vulgo cristiano ha desterrado el arte divinatoria de su seno, y estas solo sobreviven en las naciones ajenas a la fe de Cristo:

“(...) reyna aun en las naciones civiles que profesan el Paganismo, el Mahometismo, y otras sectas. Apenas hay nación en Asia (en donde están las naciones más civiles, que no son Christianas) que no respete el arte divinatoria, como a ciencia divina; y este respecto es causa de las acciones más inhumanas

\footnotetext{
32 Ibid.Tomo IV: 97.

33 Ibid.Tomo IV: 102.

${ }^{34}$ Hervás y Panduro, 1789: 142.
} 


$$
\text { en algunos países (...)”35. }
$$

Volviendo al Viage Estático, vemos nuevamente como Hervás y Panduro asocia directamente a la creencia en la astrología con la ignorancia, y como ubica estas creencias temporal y geográficamente fuera del mundo cristiano. Uno de los ejemplos más patentes de la ignorancia que se encuentra fuera del cristianismo es la idolatría generalizada hacia el Sol que existió en los pueblos de la antigüedad, en los pueblos de América y que aun existe en las naciones más civilizadas extra-europeas como China. ${ }^{36}$ No obstante, este no es el único ejemplo que utiliza Hervás para contrastar las diferencias entre el mundo cristiano ilustrado y el oriente ignorante y pagano. En el tomo IV, un poco antes de comenzar su discurso sobre los cometas, Hervás y Panduro dedica todo un capitulo a un nuevo planeta descubierto recientemente, en 1781, en el Sistema Solar: Urano. Sobre este descubrimiento nos dice, entre otras cosas, lo siguiente:

“(...) No puedo menos de decirte, que la noticia del descubrimiento de Urano, tan ruidosa entre los Europeos, se recibirá quizá con risa entre muchas naciones orientales, que profesan la Religion Brahmana del Indostan: pues en los libros sagrados de esta (la astronomía es parte principal de ellos) se lee, que los planetas solares son, no siete, como decían los antiguos Egipcios, Griegos y Romanos, y como han dicho todos los Astrónomos Europeos hasta el año 1781, sino nueve. Ten la bondad de oír las noticias que se saben sobre el numero de planetas, que en su astronomía ponen los Brahmanes”37.

Aunque en este caso Hervás hace uso de la palabra "astronomía” para describir la forma en que los pueblos de la India observan los cielos, inmediatamente a continuación se dedica a relacionar esta práctica con absurdas creencias - según Hervásen divinidades que influyen en la generación de eclipses funestos para los hombres. Es clara entonces la relación que Hervás realiza: solo los pueblos bárbaros pueden creer en la astrología o adjudicarles a los astros alguna relación con el mundo sobrenatural. En cambio, gracias a la religión cristiana y al avance de las ciencias (la física newtoniana y la astronomía) el mundo cristiano está libre de estas creencias sin fundamentos.

Luego de analizar los dichos de Hervás y Panduro sobre la astrología nos llaman la atención algunas cuestiones puntuales.

En primer lugar, como ya hemos dicho, lo primero que es evidente son las pocas páginas dedicadas a este tema a lo largo de toda su obra. En segundo lugar, y quizás esto es un poco más relevante, a lo largo de las páginas escritas por nuestro jesuita existe solo una referencia, ya mencionada, a la astrología como una disciplina supersticiosa. Esta caracterización de la disciplina astrológica por parte de Hervás -que parece haber lanzado ese epíteto sin mucha reflexión- parece estar ligeramente relacionada con el esquema tripartito de causalidad cristiano aunque con algunas variaciones. Según nuestro jesuita, los pueblos que practican esta arte divinatoria lo hacen de pura ignorancia, sea de la fe cristiana, sea del verdadero funcionamiento del mundo

\footnotetext{
${ }^{35}$ Ibid.: 141.

${ }^{36}$ Hervás y Panduro, 1793-94. Tomo II: 1-30.

${ }^{37}$ Ibid. Tomo IV: 6.
} 
explicado por las ciencias modernas. Dicho de otra manera: estos pueblos desconocen las verdaderas causalidades del orden natural. Sin embargo, Hervás y Panduro se aleja de este esquema tripartito en un punto: en ningún momento de su obra menciona la posibilidad de intervención de espíritus malignos en las predicciones astrológicas. A diferencia de Feijoo, que al menos dejaba abierta la puerta a esa chance, Hervás ni siquiera la menciona. Queda preguntarse, no obstante si esta omisión de las intervenciones preternaturales se debió a que Hervás efectivamente no creía en la intervención de espíritus en sucesos naturales o a que no consideró importante seguir explayándose sobre el tema. Esto no significa, por supuesto que nuestro jesuita niegue el orden de lo sobrenatural. El mismo Viage Estático fue escrito no solo como un mero tratado de difusión científico, sino que con el mismo Hervás pretendía demostrar la grandeza de Dios que había ordenado de manera tan perfecta el Cosmos.

Debemos entonces responder la pregunta de porque Hervás y Panduro dedicó tan poco espacio al tema de la astrología. Para intentar comprender y dar algunas respuestas tentativas a este interrogante debemos volver a dos de las obras escritas por Hervás mencionadas más arriba: Causas de la Revolución de Francia y Biblioteca Jesuíticoespañola. Ambas obras fueron escritas casi en simultáneo en durante un periodo política y religiosamente traumático: la Revolución Francesa. Sin embargo, algo que es quizás menos evidente es que también fueron escritas durante un tiempo extremadamente complejo para los (ex) jesuitas como Hervás y Panduro: cuando estas obras vieron la luz la Compañía de Jesús hacia casi veinte años que había sido extinguida por parte del Papado. Por lo tanto, estas obras pueden servirnos para entender un poco más las motivaciones de Hervás y Panduro detrás de su escritura.

La Biblioteca Jesuítico-española nos puede servir para contextualizar un poco mejor los escritos de Hervás en el contexto de la producción literaria de los jesuitas expulsos. Si revisamos en detalle el extenso listado de casi 500 autores nombrados en ella y sus más de 2000 obras nos sorprenderemos en no encontrar entre las mismas obra alguna dedicada a la astrología u otras disciplinas esotéricas. Ahora bien, esto no significa que en este repertorio no existan obras de polémica contra los "enemigos de la Fe" u obras de apologética cristiana: los jesuitas expulsos siguieron produciendo una innumerable cantidad de las mismas, aunque ahora los "adversarios" de la Iglesia o de la Compañía habían cambiado. Ya no era importante atacar con la pluma a las supersticiones del pueblo cristiano, sino que a fines del siglo XVIII existían enemigos mucho más concretos y peligrosos que derrotar. Nos estamos refiriendo a los revolucionarios franceses, sus imitadores europeos y sus maestros, según los jesuitas, los filósofos ilustrados. De las obras de carácter apologético reseñadas en la Biblioteca Jesuítico-española la gran mayoría está destinada a atacar y refutar las obras y las ideas de los philosophes y del gobierno revolucionario francés. La astrología no figura como prioridad en las obras de polémica jesuítica a finales del siglo XVIII ${ }^{38}$.

Volvamos ahora a Causas de la Revolución de Francia. Si volvemos a lo dicho más arriba, recordaremos que este libro de Hervás es sobre todo un tratado apologético que intenta defenderse de la supuesta conspiración ilustrada contra el Trono y el Altar. Las preocupaciones político/teológicas de nuestro jesuita no son la refutación de supersticiones, sino más bien atacar a los philosophes y demás enemigos de la Iglesia y

\footnotetext{
${ }^{38}$ Perrone, 2012.
} 
las Monarquías europeas. A lo largo de todo este libro Hervás cita, para refutarlos, fragmentos de textos de personajes notables como Voltaire que atacan al cristianismo y a sus creencias tildándolas de "supersticiosas", tal como hemos visto en la descripción del "modelo científico-racionalista” de superstición.

Aunque, como dijimos anteriormente, no podemos saber con certeza de que manera adscribió (o si adscribió siquiera) Lorenzo Hervás y Panduro al "modelo cristiano" de superstición, lo cierto es que dentro de su proyecto de difusión científica no parece haber habido mucho lugar para la lucha contra las supersticiones en general o la astrología en particular. Esto puede explicarse, quizás, si además tenemos en cuenta las distintas etapas de "desarrollo" de la Ilustración. Mientras que a Feijoo, que escribe en las primeras décadas del siglo XVIII, se lo puede considerar un escritor de la temprana Ilustración española, a Hervás y Panduro habría que ubicarlo en una Ilustración más tardía. Una Ilustración española que si bien quizás perdió sus elementos más progresistas, a causa de la difusión de las ideas más radicales del norte y sobre todo por la aparición del peligro revolucionario francés, ${ }^{39}$ también avanzó a lo largo del siglo con su proyecto de difusión del conocimiento práctico y del científico. Si al comienzo del siglo XVIII parecía necesario para el monje benedictino llevar adelante una intensa campaña literaria contra las supersticiones del pueblo, para nuestro jesuita, que escribió a finales del mismo siglo, esta necesidad se encuentra ausente.

Recapitulando, podemos plantear dos posibles respuestas al interrogante de la mínima presencia del discurso anti-astrológico en las obras de Hervás y Panduro. En primer lugar, es posible que ante el avance de la Ilustración y sus ideas Hervás no vea la necesidad ya de tener que dedicarse a refutar extensamente a la astrología u otras disciplinas esotéricas. De hecho, si volvemos a comparar la producción de Hervás con la de otros jesuitas (vía la Biblioteca Jesuitico-espanola) dedicados a la divulgación científica, veremos que ninguno de ellos, como ya hemos dicho, han dedicado obra alguna a la refutación de supersticiones. Obviamente, esto no nos demuestra que las campañas ilustradas antisupersticiosas hayan sido efectivas y que, por lo tanto, las "supersticiones" hayan sido eliminadas del pueblo. Lo que si puede llegar a indicar este dato es una mutación en el foco de interés de los escritores ilustrados dentro de la Compañía de Jesús. Queda por preguntarse, como también hemos señalado anteriormente, si este cambio de interés está relacionado con una transformación del “modelo cristiano" de superstición en Hervás y otros jesuitas. Por último, podría afirmarse que la apologética jesuítica sufrió una transformación en los últimos años del siglo XVIII: la lucha contra las supersticiones no era una prioridad literaria con los peligros de los revolucionarios tocando la puerta.

\section{Bibliografía}

Acuña, Constanza (ed.) (2012), La curiosidad infinita de Athanasius Kircher. Una lectura a sus libros encontrados en la Biblioteca Nacional de Chile, Santiago de Chile: Ocholibros editores.

\footnotetext{
${ }^{39}$ Gil Novales, 1988.
} 
Albiña, S. (1994), "Notas sobre la decadencia y el arbitrismo". Estudis, Revista de Historia Moderna. En torno al XVII hispánico. Valencia, Num. 20, pp 9-28.

Astorgano Abajo, Antonio (2010), El abate Lorenzo Hervás y Panduro (1735-1809). Sabio polígrafo, Ciudad Real: Almud-Universidad Castilla-La Mancha, 2010.

Batllori, Miguel (1966), La cultura hispano-italiana de los jesuitas expulsos, . Madrid, Gredos.

Bubello, Juan Pablo (2010), Historia del esoterismo en la Argentina. Practicas, representaciones y persecuciones de curanderos, espiritistas, astrólogos y otros esoteristas, Buenos Aires: Editorial Biblos.

Caballero, Fermin (1868), Conquenses Ilustres. I. Abate Hervas. Madrid: Imprenta del Colegio de Sordomudos.

Campagne, Fabian (2002), Homo Catholicus. Homo Superstitiosus. El discurso antisupersticioso en la España de los siglos XV a XVIII, Buenos Aires: Miño Dávila.

Feijoo, Benito Jeronimo (1778), Teatro Critico Universal o Discursos varios en todo género de materias, para desengaño de los errores comunes. Tomo I, Madrid: D. Joachin Ibarra, impresor de cámara de S.M., Madrid.

Fernández Sebastián, J. (1998), “Península Ibérica”. En Ferrone, V y Roche, D. (dirs), Diccionario histórico de la Ilustración, Madrid: Alianza Editorial, pp. 340-351.

Findlen, Paula (ed.) (2004), Athanasius Kircher: The Last Man Who Knew Everything, Londres: Routledge.

Findlen, Paula (2003), "Scientific Spectacle in Baroque Rome: Athanasius Kircher and the Roman College Museum”. En Feingold, Mordechai (ed.), Jesuit Science and the Republic of Letters, Cambridge: The MIT Press, pp. 225-284.

García Cárcel, R. (1998), Las Culturas del Siglo de Oro, Madrid: Historia 16.

García de Paredes Aued, G . (1964), El pensamiento de don Lorenzo Hervás y Panduro. Su significación en las ciencias del espíritu, Madrid: Artes Gráficas Mag., [s.l., s.i., s.a.]

Gil Novales, Alberto (1988), "El susto de Floridablanca”. Revista de Historia das Ideias, Coimbra, Vol 10, Universidade de Coimbra, pp. 9-22.

Hazard, P. (1988), El pensamiento europeo en el siglo xviii, Madrid: Alianza Editorial.

Hervás y Panduro, Lorenzo (2007), Biblioteca Jesuítico-española (1759-1799), Madrid: Libris.

(1807), Causas de la Revolución de Francia en el año 1789, y medios de 
que se han valido para efectuarla los enemigos de la religión y del estado. Tomos I y II, Madrid.

(1793-4), Viage Estático al Mundo Planetario en el que se observan el mecanismo y los principales fenómenos del Cielo; se indagan sus causas físicas; y se demuestra la existencia de Dios, y sus admirables atributos. 4 tomos, Madrid.

(1789), Historia de la Vida del Hombre. Tomo I. Concepción, Nacimiento, Infancia y Niñez del Hombre, Madrid.

Herr, Richard (1962), España y la revolución del siglo XVIII, Madrid: Aguilar.

Justo, María de la Soledad (2001), "Estudio introductorio. El Viage estático de Lorenzo Hervás y Panduro. La difusión científica entre los límites de la fe y la razón”. En Hervás y Panduro, Lorenzo, Viage Estático. Buenos Aires: Facultad de Filosofia y Letras, Universidad de Buenos Aires, pp. 9-98.

Herrero, Javier (1988), Los orígenes del pensamiento reaccionario español, Madrid: Alianza Editorial.

Millones Figueroa, Domingo (2005), "La intelligentsia jesuita y la naturaleza del Nuevo Mundo en el siglo XVII”. En Millones Figueroa, Luis y Ledezma, Domingo (eds.), El saber de los jesuitas, historias naturales y el Nuevo Mundo, Madrid: Iberoamericana, pp. 27-52

Leitao, Henrique (2007), "Entering Dangerous Ground: Jesuit Teaching Astrology and Chiromancy in Lisbon”. En O'Malley John S.J., Bailey, Gauvin Alexander y Harris, Steven (eds.), The Jesuits II. Culture, Sciences and the Arts, 1540-1773, Toronto: Universitiy of Toronto Press, pp. 371-389.

O' Malley, John S.J. (1994), The First Jesuits, Cambridge: Harvard University Press.

Perrone, N. (2012), "Una mirada a la comunidad de jesuitas americanos expulsos a través de las obras de Lorenzo Hervás y Panduro S.J. (1735-1809)” Historia UNISINOS, Vol 16 - N¹, Enero-Abril 2012, Universidade do Vale do Rio dos Sinos - Unidade Academica de Pesquisa e Pos-Graduaçao Editoria de Periódicos Científicos, pp. 106-117.

(2010), Reseña de "Lorenzo Hervás y Panduro, Biblioteca Jesuíticoespañola (1759-1799), Madrid, Libris, 2007; Biblioteca Jesuítico-española II. Manuscritos hispano-portugueses en siete bibliotecas de Roma, ed. Antonio Astorgano Abajo, Madrid, Libris, 2009.” Olivar. Revista de Literatura y Cultura Españolas, La Plata, Nro 15, pp. 205-210

Sánchez-Blanco Parody, F. (1991), Europa y el pensamiento español del siglo XVIII, Madrid: Alianza.

Sarrailh, Jean (1981), La España ilustrada de la segunda mitad del siglo XVIII, Mexico: 
FCE.

Stolzenberg, Daniel (2007), "Utility, Edification, and Superstition: Jesuit Censorship and Athanasius Kircher's Oedipus Aegyptiacus”. En O'Malley John S.J., Bailey, Gauvin Alexander y Harris, Steven (eds.), The Jesuits II. Culture, Sciences and the Arts, 1540-1773, Toronto: Universitiy of Toronto Press, pp. 336-354. 